\title{
A review of single phase adaptive auto- reclosing schemes for EHV transmission lines
}

\author{
Waqar Ahmad Khan ${ }^{1,2^{*}}$ (D) Tianshu Bi ${ }^{1}$ and Ke Jia ${ }^{1}$
}

\begin{abstract}
Statistics shows that transients produced by lightning or momentary links with external objects, have produced more than $80 \%$ of faults in overhead lines. Reclosing of circuit breaker (CB) after a pre-defined dead time is very common however reclosing onto permanent faults may damage the power system stability and aggravate severe damage to the system. Thus, adaptive single-phase auto-reclosing (ASPAR) based on investigating existing electrical signals has fascinated engineers and researchers. An ASPAR blocks CB reclosing onto permanent faults and allows reclosing permission once secondary arc is quenched. To address the subject, there have been many ASPARs techniques proposed based on the features trapped in a faulty phase. This paper presents a critical survey of adaptive auto-reclosing schemes that have hitherto been applied to EHV transmission lines.
\end{abstract}

Keywords: Adaptive auto-reclosing, Protection, EHV transmission lines, Temporary faults, Permanent faults

\section{Introduction}

Autoreclosure can be defined as the process of "automatically intersecting and reclosing an alternatingcurrent circuit with a programmed sequence of opening and reclosing followed by resetting, hold closed, or lockout" [1]. Overhead transmission lines undergo two types of faults i.e. temporary and permanent fault. Statistical surveys depicts that, more than $80 \%$ of faults on overhead lines are temporary in nature. As the temporary faults resides for only a short period of time, therefore they can be eliminated by just isolating the faulted phase. Hence, ensuring maximum power system stability and not letting the problem reach more equipment. On the other hand, permanent faults cannot be cleared until they are fixed. Hence, false reclosing i.e. reclosing during permanent faults may intensify the potential damage to the system. Based on the above discussion, temporary faults can be cleared by opening the circuit breaker (CB) and deionisation of the arc path. Therefore the opportunity of restoring power arises.

\footnotetext{
* Correspondence: waqarahmed_khan@hotmail.com

${ }^{1}$ State Key Laboratory for Alternate Electrical Power System with Renewable Energy Sources, North China Electric Power University, Beijing 102206,

People's Republic of China

${ }^{2}$ Faculty of Engineering, Lahore Leads University, Lahore, Punjab, Pakistan
}

Due to the large number of HVDC links in china, the multi infeed scenario are being formed in the north east coastal region; which makes the power system more complex and vulnerable. Therefore even a transient fault can become a great threat for present power system. According to the present status of Chinese power grid, HVDC transmission is employed to transmit bulk power over the long distances. It is commonly documented that the successful operation of HVDC transmission depends largely on the voltage level of the converter buses. Therefore a fault on HVAC side would adversely affect the HVDC side too.

During a fault scenario, the power system can observe two disturbances. One, when there is a fault on a transmission line. The faulted phase is isolated from either ends of the line by conventional protection. Two, when reclosing is performed without identifying the fault nature i.e. onto permanent fault. Hence it is mandatory to first identify the fault nature and to minimize the fault duration. By shortening the fault duration, probability of commutation failure on HVDC side can also be reduced.

Owing to these concerns some smart and quick ways of single phase auto reclosing (SPAR) are gaining attention worldwide. The use of SPAR manoeuvre is most appropriate for single-phase faults, since the transmission 
lines can still permit more than half of their nominal power, hence improving the system consistency and stability [2]. The SPAR methodologies can be divided into two classes: traditional [2-6] and adaptive [7-10] autoreclosing.

Traditional single-phase auto-reclosing schemes are employed with fixed dead time and are unable to identify the fault nature. Which means the re-closing can be initiated during the fault or reclosing can reinitiate the fault and causes over-voltages across the circuit breaker [11, 12].

To overcome the limitations of traditional auto reclosing schemes, some adaptive auto reclosing schemes were introduced in the past, which are called ASPAR. These techniques can be divided into two main categories i.e. communication or both ends data based and noncommunication or local end data based methodologies. These methodologies can be further classified on the basis of time domain, frequency domain and timefrequency domains analysis [13-17]. In each of these methodologies, voltage, current or both signals are examined to discriminate between temporary and permanent faults and to detect the arc extinction instant.

In this paper, the authors will discuss details about different existing ASPAR methodologies around the world. This paper provides the deep understandings into the adaptive autoreclosing. The contribution of this paper is to highlight the positives and negatives of each methodology which are utilized in the implementation or study in order to guide engineers and researchers.

The paper is organized in four sections. Section 2 discusses adaptive autoreclosure Section 3 discusses research overview in adaptive autoreclosing Section 4 concludes the paper.

\section{Adaptive autoreclosure}

The principal objective of an Adaptive Autoreclosing (AA) scheme is to detect the soonest and safest reenergization moment without inviting secondary trips. The basic ASPAR operation is shown in Fig. 1.

The various stages of an ASPAR scheme can be clearly seen in Fig. 1. Figure 1a shows the normal operation or pre-fault condition of a power system. A single line to ground fault (transient or permanent) is incepted on a phase as shown in Fig. 1b. Faulted phase is isolated by the conventional protection and can be seen in Fig. 1c. Fault nature identification is performed and in case of a transient fault, wait for the secondary to be completely extinguished, see Fig. 1d. Figure 1e shows that the arc is extinguished and now it is safe to reclose the faulted phase.

A temporary fault also involves the determination of arc extinction [8, 9, 18-20]. Any ASPAR scheme first determines the fault nature i.e. it differentiates between a temporary and a permanent fault. If a permanent fault is spotted, reclosing is blocked. Otherwise, the scheme looks for an arc extinction instant before reclosing. After the extinction of secondary arc, residual voltages will appear on the line which is an indication for a safest reclosing instant. This single phase tripping operation can only be tolerable for a few seconds. Otherwise this unbalanced condition can challenge the stability of the whole power system.

Circuit breakers play a vital role in any AA scheme as the reclosing decision is heavily dependent on the post fault information. Therefore most AA schemes utilizes the presence of secondary arc for decision making. Keeping the above mentioned facts in mind, an adaptive autoreclosure must have the following traits [21]:

- It can discriminate between permanent and temporary faults efficiently.

- It can determine the moment of secondary arc extinction.

- It can define an optimum reclosure time [22].

- It cannot be affected by varying power system operating conditions.

- It should ensure stability although there are some changes in network topology

\section{Research overview in adaptive autoreclosing}

Adaptive autoreclosing techniques are mainly focused on discrimination of temporary and permanent faults and the identification of safest reclosing instant, in case of temporary faults. These techniques are classified into two categories i.e. non-communication or local end data based and communication or both ends data based.

\subsection{Non-communication or local end data based ASPAR schemes}

Discrimination between permanent and temporary faults based on local end data was first introduced in early 1990s [23]. Voltage and current values from the local end terminal are obtained and analyzed. A key benefit by this is that communications channels are not required. Non-communication based methodologies can further be classified on the basis of their domain, utilised for analysis i.e. time domain, frequency domain and time-frequency domain analysis. A review of ASPAR techniques based on the criteria discussed above with their advantages and technical limitations are presented in this section.

\subsubsection{Time domain analysis based}

Time domain analysis referred to as an analysis of any mathematical function or a physical signal with 

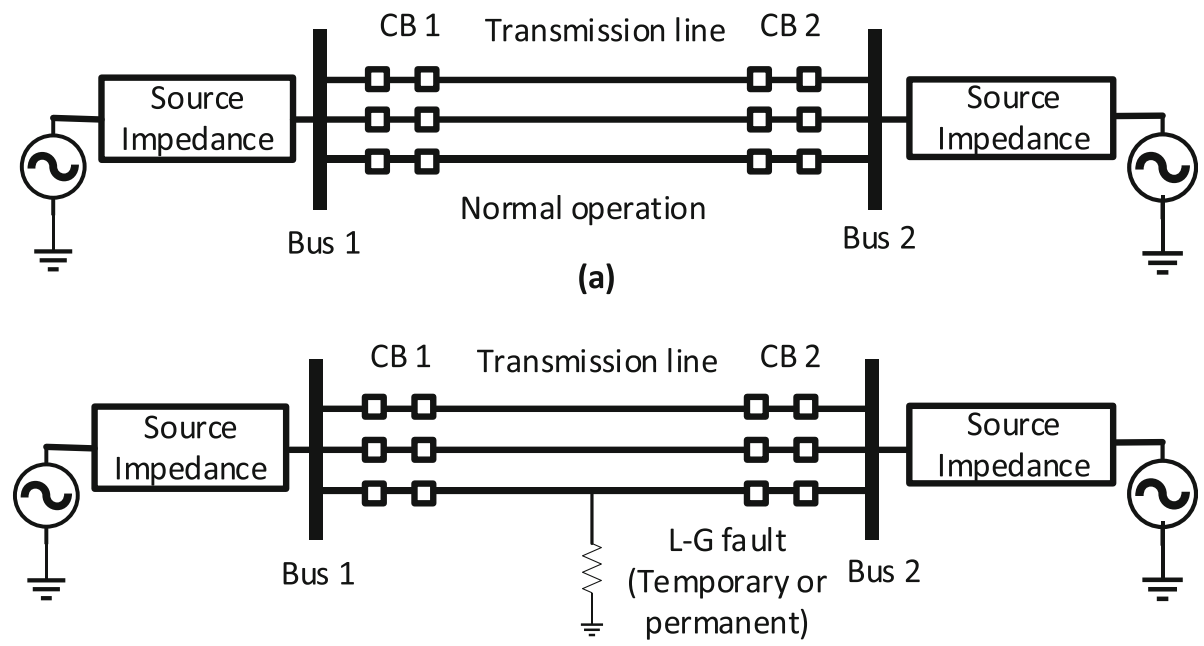

(b)

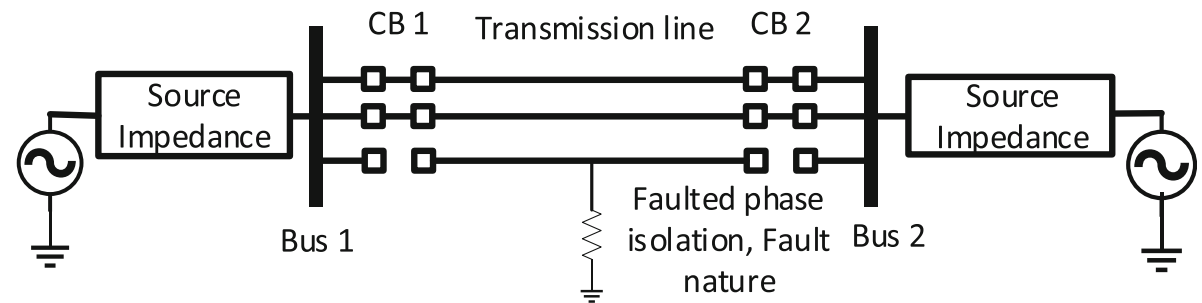

(c) identification

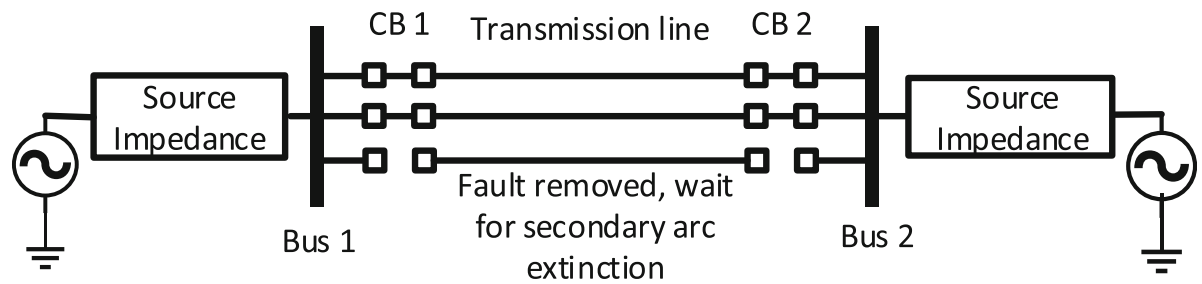

(d)

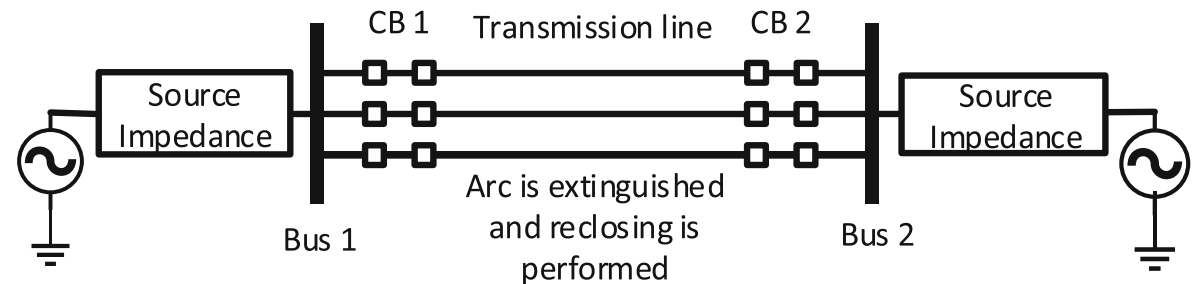

(e)

Fig. 1 Basic operation of an ASPAR scheme

respect to time. It was first developed in the late 1940s. Time domain analysis is used to identify the behavior of a signal at a specific instant. Also it can give information about how a signal changes with time. Time domain analysis based techniques are discussed below.

Adaptive cumulative sum method (ACUSUM) based ASPAR scheme is presented in [19]. It detects the amplitude changes in the faulted phase voltages. Amplitude of the faulted phase voltages changes, whenever the fault is incepted, circuit breaker is opened and the secondary arc is quenched. Whenever a phase experiences a fault, the current goes up and the voltages goes down to keep the balance in power input and output. Therefore ACUSUM detects these changes in voltage magnitude and counts for two decrements followed by one increment. Increment in voltage amplitude gives an indication that the secondary arc is quenched and a reclosing command is sent to the circuit breaker. This technique possess some 
technical challenges. The voltage waveform depends on the type of fault i.e. the voltage rises with growing fault impedance [23]. Also, the fault can reinitiate upon reclosing therefore no deionization time delay is provided.

Another ACUSUM based methodology is discussed in [24]. After the secondary arc extinction a delay named (Delay 3 ) is provided for the arc path to be completely deionized so that fault cannot re-initiate itself. Then in case of a temporary fault, ACUSUM detects an amplitude increment in the faulted phase voltages and a reclosing command is sent to $\mathrm{CB}$. Although deionization time delay is provided, but still this scheme cannot be implemented in practical power system as shunt reactors are not considered for simulation studies. Residual voltages show swing behavior after the secondary arc is extinguished therefore shunt compensated transmission lines must be considered.

A novel method based on zero sequence voltages is presented in [17]. As the zero sequence voltages only appear in case of fault and are in phase with the other phases, therefore the zero sequence voltages are measured at the relay point after the $\mathrm{CB}$ opening. An index is generated by estimating the mean value of the zero sequence voltages which have a non-zero value in case of temporary fault at the instant when the secondary arc is quenched. The scheme presented is adaptive in nature and don't need any pre-defined threshold value. It provide simple solution for distinguishing between permanent and temporary faults.

Adaptive Linear Neuron (ADALINE) based autoreclosing scheme is discussed in [25]. By which error signal is generated by comparing the present value of the terminal voltages with the previous one. During the fault, an error signal is created by computing the change in magnitude of the terminal voltages. ADALINE is used because of its adaptive signal predictive nature, it can detect the change in input signal immediately [26-28]. Time Average of Error Signal (TAES) [29] is calculated as the error signal shows non-linear behavior. In case of a temporary fault TAES sharply increases and after the arc extinction, it decays slowly. While in case of permanent fault, TAES sharply increases and will never decay. This fact is used to identify the fault nature and to indicate the secondary arc extinction instant. It is fast enough to detect a change in the input signal [30]. There are some limitations as the voltage magnitude depends upon fault current and fault location therefore it is difficult to analyze non-linear behavior of the terminal voltages. It may not work for an unaccounted situation.

The techniques presented in this section are well suited for single phase adaptive autoreclosing application. Their advantages and technical limitations are as under:

- The reclosing time is very short which is very good for power system stability.
- Deionization time delay is provided which is mandatory to ensure the extinction of the secondary arc.

- As the voltage rises with growing fault impedance, therefore voltage amplitude may rise instead of decreasing.

- Optimal dead time for secondary arc must be determined for safe reclosing.

- Magnitude of the zero sequence voltages depend upon the magnitude of the fault current. Due to the presence of noise, it would be difficult to evaluate mean value of zero sequence voltages and hence to discriminate between temporary and permanent fault.

- Practical application of different ASPAR schemes is not possible as the actual power system is not considered.

\subsubsection{Frequency domain analysis based}

Frequency domain analysis was first introduced in early 1960s. It is the analysis of any signal or mathematical function with respect to frequency. Techniques based on frequency domain analysis are discussed below.

A numerical algorithm is presented in [16] which utilizes total harmonic distortion (THD)\% to classify temporary and permanent faults. This algorithm is suitable for defining adaptive dead time, and obstructing automatic reclosing during permanent faults. The arc produced in case of a transient fault, is a source of higher harmonics. Therefore THD is calculated to identify the fault nature. Discrete Fourier transform (DFT) is applied to the faulted phase voltages to calculate THD factor. A non-linear nature of the arcing faults on a transmission line, causes the distortion of the arc voltage $[31,32]$. Therefore, THD\% has a greater value during the secondary arc and it has a small value after the arc extinction. This will give an indication that the arc is quenched and now it is safe to reclose.

PRONY based numerical algorithm is presented in [33]. The technique utilizes the swing behavior of waveform, produced due to the presence of shunt reactors, to identify the fault nature. In case of a temporary fault the current in the shunt reactor has a low frequency component. When it combines with the power frequency component, due to the mutual coupling between phases, a swing behavior of waveform is produced. While there is only power frequency component of current in the open phase is present in case of permanent fault. As the voltage magnitude depends on the load currents and fault resistance, therefore it would be problematic to assess the voltage magnitude and hence to differentiate between permanent and temporary faults [23].

Shunt compensated transmission lines are addressed in [34]. For the shunt-compensated transmission lines, after the arc disappearance, the residual voltages show an oscillating behavior due to the mutual coupling between lines 
and the shunt reactor's inductance. This wave shape may contain different frequency components. The proposed adaptive reclosing methodology uses the fundamental value of the faulted phase voltage to define the fault nature but to calculate the spectral and temporary energies of an actual power system is not an easy task to perform.

Recovery voltages show different frequency characteristics in different situations. A new method based on power spectrum is proposed in [35]. During the temporary fault period, there will be high frequency components in the bus voltages at primary arc stage. During the secondary arc phase, due to the non-linear behavior of the arc, residual voltages comprises of power and resonant frequency components. While the recovery voltage only have power frequency component in case of a permanent fault. Amplitude and resonant frequency components are then utilized to determine the fault nature. However the above mentioned technique is very useful in determining the fault nature and the appropriate reclosing instant but the relationship of several factors such as line parameters, fault position, pre-fault loading, source constraints, and atmospheric conditions which effect the actual waveforms of the secondary arc, may impede the effectiveness of this technique.

The pros and cons of the techniques presented in this section are:

- Shunt compensated transmission lines are discussed in some techniques for their swing behavior of residual voltages.

- Actual power system is considered for simulation studies. Which increases the adaptability of the proposed schemes.

- Secondary arc is the combination of low and high frequency components, therefore it would be a hectic task to calculate THD\% accurately.

- Due to the higher voltage level secondary arc will take longer time to decay therefore an optimal dead time must be determined before reclosing.

- Swing behavior appears in shunt compensated transmission lines, can help secondary arc to reside for longer time.

\subsubsection{Time-frequency domain analysis based}

Time-frequency domain analysis was first introduced in 1909 in Haar wavelets. It can provide information in both time and frequency domain at the same time. Time-frequency domain based techniques are discussed in this section [36, 37].

Wavelet packet transform (WPT) based adaptive autoreclosing scheme is presented in [38] for its richer range of possibilities for signal analysis. WPT is used to decompose the faulted phase voltages into its detailed coefficients by using low and high pass filters. The values of these coefficients are then added to define an index which will have a higher value in case of a temporary fault and remains zero for permanent faults. Moreover when the index has a zero value in case of temporary faults, it is an indication of secondary arc quenching. Reactor compensated transmission lines are also discussed in this paper due to their swing effect on the faulted phase voltages [22, 39]. This technique is suitable for both reactor compensated and uncompensated transmission lines.

Wavelet transform (WT) and adaptive fuzzy neuro inference (ANFIS) based adaptive autoreclosing scheme is presented in [40]. ANFIS is an efficient pattern classifier based on its training [41]. Wavelet transformation is used for signal processing and ANFIS for its wide range of logic sets to differentiate between permanent and temporary faults. Using the low and high pass filters, the terminal voltages are decomposed into its coefficients [42]. In case of temporary fault, the percentage of energy of these coefficients is greater than zero, and in case of permanent fault, it remains close to zero. This fact is used to discriminate between permanent and temporary faults. It is robust against noise but fuzzy logic needs predefined logic sets which cannot be improved once established [43, 44].

The advantages and disadvantages of the above discussed techniques are:

- Wavelet analysis gives information in both time and frequency domains.

- The response of a signal in time and frequency domains can be separately observed.

- AI based techniques perform well for the problems it is trained.

- It depends upon the applied mother wavelet [45] and decomposition of a signal into its detailed coefficients needs an extensive computational burden.

- Artificial intelligence based algorithms needs an extensive training before implementation.

- They are useless for an unaccounted situation.

- Training of an ANN $[46,47]$ is a burdensome job to do

A brief summary of ASPAR schemes mentioned in the above section is presented in Table 1. Table 1 gives information of different ASPAR techniques in terms of their reclosing time, transmission system utilised for simulation studies, input values to an ASPAR and the methods.

\subsection{Communication or both ends data based ASPAR schemes}

The technology of obtaining data from both ends of a transmission line for adaptive autoreclosing application, was first established in 1989. It offers an ideal measurement system by comparing the values of either ends, to observe and control a power system [48]. The vital feature of the technique is that it is suitable for widely 
Table 1 Summary of local end data based ASPAR schemes

\begin{tabular}{|c|c|c|c|c|c|}
\hline Method & Transmission system & $\begin{array}{l}\text { Reclosing } \\
\text { time }\end{array}$ & Inputs & Remarks & Reference \\
\hline ACUSUM & Uncompensated & $4 \mathrm{~ms}$ & Faulted phase voltages & Simple, easy and much faster than others & [19] \\
\hline ACUSUM & Uncompensated & - & Faulted phase voltages & $\begin{array}{l}\text { Inclusion of deionization delay is good } \\
\text { however practical system is not discussed }\end{array}$ & [24] \\
\hline DFT \& THD & Uncompensated & $20 \mathrm{~ms}$ & Faulted phase voltages & $\begin{array}{l}\text { No time localization of the fault, little bit } \\
\text { slower }\end{array}$ & [16] \\
\hline PRONY signal analysis & Shunt compensated & - & Current present in shunt reactor & $\begin{array}{l}\text { Higher values of voltages may extend } \\
\text { the time for secondary arc to extinguish }\end{array}$ & [33] \\
\hline DFT \& THD & Uncompensated & $8 \mathrm{~ms}$ & Zero sequence voltages & $\begin{array}{l}\text { Short reclosing time but noise can } \\
\text { disrupt the calculations }\end{array}$ & {$[17]$} \\
\hline WPT & Shunt compensated & $5 \mathrm{~ms}$ & Faulted phase voltages & $\begin{array}{l}\text { Faster and provides both time and } \\
\text { frequency localization of the fault }\end{array}$ & [38] \\
\hline Numerical Algorithm & Shunt compensated & $0.7 \mathrm{~s}$ & Faulted phase voltages & Need a lot of mathematical computation & [34] \\
\hline Power spectrum analysis & Shunt compensated & - & Recovery voltages & Simple and easy to implement & [35] \\
\hline ADALINE & Uncompensated & - & Faulted phase voltage signal & $\begin{array}{l}\text { Easy to determine fault nature. However } \\
\text { practical system is not discussed }\end{array}$ & [25] \\
\hline WT \& ANFIS & Uncompensated & $270 \mathrm{~ms}$ & Faulted phase voltage signal & $\begin{array}{l}\text { An intelligent fault classifier based on } \\
\text { pattern recognition }\end{array}$ & {$[18,19,40$} \\
\hline
\end{tabular}

separated locations [49, 50]. Communication based adaptive autoreclosing schemes can further be classified on the basis of time domain and frequency domain analysis. Techniques lies in the categories discussed above with their technical limitations are discussed in this section.

\subsubsection{Time domain analysis based}

A synchrophasor based adaptive autoreclosing technique is presented in [51]. The algorithm discriminate the fault type by measuring the synchronized data of healthy phases at both ends of the line. By computing the current values on either sides of the line, an index is generated. In case of any fault, one of the current becomes erroneous, and if the fault is temporary in nature, the index becomes zero after the secondary arc extinction. This fact is used to differentiate between temporary and permanent faults and to define a reclosing instant. While obtaining the data from both ends of the line accurately, noise free proper communication channel is required. Which may increase the cost of the entire scheme.

Another communication aided technique is presented in [11], by which faulted phase voltages are predicted by using the information of healthy phases at the instant of CB tripping and secondary arc disappearance on either ends. Magnitude and phase angle of the voltage are monitored to detect the arc elimination instant. Permanent fault is identified, when the voltage magnitude and phase angle shows similarity for a few cycles, after the circuit breakers are interrupted from both ends [52]. Therefore, both the magnitude and angle derivation is used to detect the permanent fault. Although the synchrophasor based measurement techniques gaining more attention but they possess some issues. It is presented in [23] that (i) the voltage magnitudes diverge significantly with load currents and fault impedance, (ii) in case of a permanent fault, actual voltage magnitude is very challenging to determine and (iii) the effect of fault impedance on the magnitude of voltage.

Adaptive autoreclosing scheme based on artificial neural network (ANN) is presented in [53]. Gabor transformation (GT) is used as an innovative signal processing tool to extract information of the faulty phase current values. On the basis of these Gabor coefficients, feedforward ANN based classifier will recognize whether it is permanent or a temporary fault. The technique has following limitations as the signal transformation requires broad computation. Faulted phase current value depends on line construction, therefore it may have different values due to the mutual coupling with other healthy phases.

Prony theory based fault nature identification for adaptive autoreclosing scheme is presented in [15]. This ANN based methodology is trained by Resilient Backpropagation and Levenberg-Marquardt algorithm. The inputs to the ANN are the faulted phase voltage waveforms obtained by applying Prony analysis (PA), a method that estimates a function with a sum of damped sinusoids. The PA effectively indicate the change in the amplitudes of both types of faults but it require extensive training and it is not immune to noise.

The techniques discussed above possess some advantages and disadvantages which are:

- Phasor data can be considered for multiple purposes, such as wide area monitoring, real time operations and for power system planning. 
- Communication based algorithms needs a noise free medium, which is indeed an expensive and difficult task to perform.

- Faulted phase current may have a different value due to the mutual coupling with the healthy phases. Therefore it is difficult to calculate the actual value of the faulted phase current.

- Mathematical algorithms require extensive training and are unable to deal with unaccounted situations.

\subsubsection{Frequency domain analysis based}

Another communication based methodology by which line currents and voltages are sampled at both ends of the line by using Phasor Measurement Units (PMU) is presented in [54]. Fast communication channels and two Intelligent Electronic Device's (IED) are installed at the line terminals. IED's are based on a predefined settings file. The testing of setting file is one of the most time consuming task. DFT is then applied for voltage and current harmonics and for phasor calculations. Then by computing the arc resistance and total fault resistance, the technique efficiently determine the fault location and fault nature (permanent or temporary). In this scheme, the communication channels require more training to transmit the data in its actual form when applied to long transmission lines.

A PMU based technique [14], in which synchronized measurement of voltages and current phasors is carried out. Global Positioning Satellite (GPS) is implemented for communication between two modules [55, 56]. Different sequences of voltage and current phasors are utilized to identify the fault nature. Faulted phase voltages are measured after the CB is open. When THD based temporary fault detector (TFD) detects a value less than the defined value for two cycles, the fault is determined as permanent fault. Before implementing this technique one should keep it in mind that GPS signals can easily be attenuated due to some hurdles to the signals such as buildings, trees and atmospheric conditions. Also a GPS device can be battery driven and needs a power supply to operate it.

Another PMU based adaptive autoreclosing technique is presented in [57]. PMU based synchronized measurement of voltage and current phasors, from both ends is carried out to calculate the impedance parameters of the line. Which means a separate and dedicated PMU require on either sides of the line which is very expensive. The variation of fault current and voltages before and after the fault incidence, measured on either ends of the line are used to define a threshold and to select that which phase is under fault. Then by THD factor value, fault type and the arc extinction instant is determined.

Zero sequence differential power based scheme is proposed in [13]. The technique utilizes the variation in the line voltages and currents. Instantaneous zero sequence power is calculated at both line terminals in order to perceive the synchronized effect of arc extinction on voltage and current waveforms. Programmable Logic Control (PLC) communication is employed to compare the values at each end. Then by DFT, the fundamental components of the power are obtained. An increase in operating power value gives an indication for secondary arc extinction.

Fault nature and fault location identification technique based on IED's installed at both line terminals, for synchronized measurements of voltage phasors is presented in [58]. GPS is used for communication between two IED's. Temporary recorder is used to record arc voltages on either ends of the line. DFT is applied to obtain the harmonic content present in voltage and current waveforms. A fault is referred as a temporary fault if the calculated value of the arc voltage amplitude is greater than the minimum arc voltage amplitude. Using GPS for communication purpose may contain some problems as GPS accuracy depends on quality of the received signals. GPS signal gets affected due to atmosphere (i.e. ionosphere), electromagnetic interference etc.

Another ADALINE based intelligent algorithm is presented in [59]. ADALINE looks for the harmonic content present in the faulted phase voltages, to discriminate between temporary and permanent faults in power transmission lines. In case of permanent fault, during secondary arc period, the value of total harmonic inverse factor (THIF) remains high. While in case of temporary faults THIF decreases after the secondary arc is quenched. The technique undergo some issues as if there is an abrupt change in the system, large error signal is generated and ADALINE may loses its ability to track the change $[60,61]$. During secondary arc period, the arc may have low and high frequency components so THIF may become erroneous.

The advantages and disadvantages of methodologies presented in this section are discussed below:

- PMU's are widely adopted for their higher scan rate and precision of data.

- It allows many real time algorithms to implement PMU's to enhance speed and accuracy.

- GPS signals can easily be attenuated by the hurdles such as buildings, trees and atmospheric conditions.

- Power supply is required to operate the GPS devices which is not always possible.

- The communication between the two PMU's via GPS require high bandwidth communication links, and noise free medium which is very difficult to create.

- As PLC is a solid state semiconductor device which is temperature dependent. Therefore after certain temperature they might malfunction. Extensive training is required to program a PLC to operate for different operations. 
Table 2 Summary of both end data based ASPAR schemes

\begin{tabular}{|c|c|c|c|c|c|}
\hline Method & $\begin{array}{l}\text { Transmission } \\
\text { system }\end{array}$ & $\begin{array}{l}\text { Reclosing } \\
\text { time }\end{array}$ & Inputs & Remarks & Reference \\
\hline Synchrophasor & Uncompensated & - & Healthy phase phasor data & $\begin{array}{l}\text { It is not easy to obtain data } \\
\text { from healthy phases due to the } \\
\text { communication channel issues }\end{array}$ & [51] \\
\hline Numerical algorithm & Uncompensated & $20 \mathrm{~ms}$ & Faulted phase voltage and current & $\begin{array}{l}\text { A little faster but needs a lot of } \\
\text { computations for IED's and DFT }\end{array}$ & [54] \\
\hline Analytical approach & Shunt compensated & $70-160 \mathrm{~ms}$ & Voltage phasor of healthy phases & $\begin{array}{l}\text { Phasor calculation is cumbersome } \\
\text { in case of permanent fault }\end{array}$ & [11] \\
\hline PMU & Shunt compensated & $131 \mathrm{~ms}$ & $\begin{array}{l}\text { Voltage and current phasor of } \\
\text { faulted phase }\end{array}$ & Little bit slower than other techniques & [14] \\
\hline PMU & Uncompensated & $20 \mathrm{~ms}$ & $\begin{array}{l}\text { Positive sequence voltage and } \\
\text { current phasor }\end{array}$ & $\begin{array}{l}\text { GPS for communication is not a good } \\
\text { choice as it is a power hungry device }\end{array}$ & [57] \\
\hline Differential approach & Uncompensated & $75 \mathrm{~ms}$ & Zero sequence instantaneous power & $\begin{array}{l}\text { PLC communication is used which is } \\
\text { good but DFT can only give frequency } \\
\text { information }\end{array}$ & [13] \\
\hline Numerical algorithm & Uncompensated & - & Faulted phase voltage and current & $\begin{array}{l}\text { Communication between IED's is } \\
\text { not easy, they can only react to } \\
\text { the predefined situations }\end{array}$ & [58] \\
\hline ADALINE NN & Uncompensated & - & Faulted phase voltages \& THD & $\begin{array}{l}\text { No time localization of fault, abrupt } \\
\text { errors can produce higher harmonics }\end{array}$ & [59] \\
\hline Gabor transform \& ANN & Uncompensated & - & Faulted phase current signal & $\begin{array}{l}\text { An effective signal transformation with } \\
\text { both time and frequency localization }\end{array}$ & {$[22,23,53]$} \\
\hline
\end{tabular}

Table 2 gives a brief comparison of different methodologies presented in this section. It compares different techniques on the basis of their reclosing time, transmission line construction, input value to an ASPAR and the methods used to implement ASPAR. Some important equations that were used in various techniques from different papers are presented in Table 3.

\section{Conclusion}

This paper provides an extensive review on the ASPAR schemes and related issues. These schemes are classified

Table 3 Summary of important equations used in different ASPAR schemes

\begin{tabular}{|c|c|c|c|}
\hline Serial & Equation & Detail & Reference \\
\hline 1 & $\begin{array}{l}V_{\operatorname{arc}}(t)=V_{\operatorname{arc}} \operatorname{sgn}[i(t)] \\
\operatorname{sgn}[i(t)]=\left\{\begin{array}{c}+1, \text { if } i(t) \geq 0 \\
-1, \text { if } i(t)<0\end{array}\right.\end{array}$ & Static arc model & {$[62-64]$} \\
\hline 2 & $\frac{d g_{p}}{d t}=\frac{1}{T_{p}}\left(G_{p}-g_{p}\right)$ & Dynamic arc model & {$[62-65]$} \\
\hline 3 & THD $\%=\frac{\sqrt{\sum_{h=2}^{5} V_{h}^{2}}}{V_{1}} 100 \%$ & Total harmonic distortion & {$[16,63,66]$} \\
\hline 4 & $\begin{array}{l}\varepsilon_{k}=X_{k}-\hat{X}_{k} \\
\text { TAES }_{k}=\frac{\sum_{k=1}^{N_{s}}\left|\varepsilon_{k}\right|}{N_{s}}\end{array}$ & Error and Time average error signal & [25] \\
\hline 5 & $\begin{array}{l}d^{1}[n]=\sum_{k=0}^{N-1} h(k) f(n-k) \\
a^{1}[n]=\sum_{k=0}^{N-1} g(k) f(n-k)\end{array}$ & First level approximation in wavelet packet transform & {$[38]$} \\
\hline 6 & $\psi^{r}=\sum_{k=1}^{n}\left(C_{M P}^{r, k} V M^{\ddot{E}^{k}}+C_{N Q}^{r, k} V N^{\ddot{E}^{k}}+D_{M P}^{r, k} k_{\lambda}^{k}\right.$ & Index value calculation in synchrophasor based ASPAR scheme & [51] \\
\hline 7 & $\begin{array}{l}P_{k}(1)=\max \left[\left(P_{k-1}(1)+V_{k}(1)-V_{d y n-k}\right), 0\right] \\
P_{k}(2)=\max \left[\left(P_{k-1}(2)+V_{k}(2)-V_{d y n-k}\right), 0\right]\end{array}$ & Basic ACUSUM algorithm for voltage amplitude detection & {$[19,24]$} \\
\hline 8 & $\begin{array}{l}X_{k}=\sum_{n=0}^{N-1} X_{n} e^{-i 2 \pi k n / N} k=0, \ldots \ldots, N-1 \\
X_{k}=\sum_{n=0}^{N-1} X_{n} e^{-\frac{2 \pi k}{N} k n}\end{array}$ & For calculating FFT and DFT of a signal & {$[16,66]$} \\
\hline
\end{tabular}


on the basis of data acquisition. Some AI techniques are also discussed. Under the paradigm of power system stability and reliability, ASPAR schemes are becoming popular since they are fast and efficient enough in fault nature determination. However, ASPAR scheme for actual power system have not been comprehensively researched. Most of the papers provide solutions for specific cases and a complete solution is not yet proposed. However, wavelet transforms are found the most effective signal processing tools so far because they provide several resolutions in both time and frequency. To speed up the wavelet transformation process FFT can be used in combination with wavelets to acquire faster reclosing. Hence this work will help researchers to develop core foundation for ASPAR in EHV transmission system.

\section{Acknowledgements}

Not applicable.

\section{Authors' contributions}

WAK has performed the literature review and collected the information pertaining to single phase adaptive autoreclosing schemes. TB and KJ provided the idea and other technical guidance required for completing the study. WAK and TB wrote, reviewed and edited the manuscript. All authors read and approve the final version of the manuscript.

\section{Funding}

Not applicable.

\section{Availability of data and materials}

Data sharing is not applicable to this article as no data were generated nor analyzed during this research.

\section{Ethics approval and consent to participate}

Not applicable.

\section{Consent for publication}

Not applicable.

\section{Competing interests}

The authors declare that they have no competing interests.

Received: 26 March 2019 Accepted: 23 September 2019

Published online: 24 October 2019

\section{References}

1. IEEE standard dictionary of electrical and electronics terms. (1979). Wiley, New York. https://doi.org/10.1109/TPS.1979.4317228.

2. Milne, K. H. (1963). Single-pole reclosing tests on long 275-Kv transmission lines. IEEE Transactions on Power Apparatus and Systems, 82, 658-661.

3. Peterson, H., \& Dravid, N. (1969). A method for reducing dead time for single-phase reclosing in EHV transmission. IEEE Transactions on Power Apparatus and Systems, 88, 286-292.

4. Kappenman, J., Sweezy, G., Koschik, V., \& Mustaphi, K. (1982). Staged fault tests with single phase reclosing on the Winnipeg-twin cities $500 \mathrm{kV}$ interconnection. IEEE Transactions on Power Apparatus and Systems, 101, 662-673.

5. Haun, R. K. (1978). 13 years' experience with single-phase reclosing at 345 KV. IEEE Transactions on Power Apparatus and Systems, 97, 520-528.

6. Esztergalyos, J., Andrichak, J., Colwel, D. H., Dawson, D. C., Jodice, J. A., Murray, T. J., Mustaphi, K. K., Nai, G. R., Politis, A., Pope, J. W., Rockefeller, G. D., Stranne, G. P., Tziouvaras, D., \& Schweitzer, E. O. (1992). Single phase tripping and auto reclosing of transmission lines-IEEE committee report. IEEE Transactions on Power Delivery, 7, 182-192.

7. Jamali, S., \& Ghaffarzadeh, N. (2011). Adaptive single pole auto-reclosing using discrete wavelet transform. European Transactions on Electrical Power, $21,973-986$
8. Zhalefar, F., Zadeh, M. R. D., \& Sidhu, T. S. (2017). A high-speed adaptive single-phase reclosing technique based on local voltage phasors. IEEE Transactions on Power Delivery, 32, 1203-1211.

9. Lin, X., Weng, H., Liu, H., Lu, W., Liu, P., \& Bo, Z. (2006). A novel adaptive single-phase reclosure scheme using dual-window transient energy ratio and mathematical morphology. IEEE Transactions on Power Delivery, 21, 1871-1877.

10. Lin, X., Liu, H., Weng, H., Liu, P., Wang, B., \& Bo, Z. Q. (2007). A dual-window transient energy ratio-based adaptive single-phase reclosure criterion for EHV transmission line. IEEE Transactions on Power Delivery, 22, 2080-2086.

11. Zadeh, M. R. D., \& Rubeena, R. (2013). Communication-aided high-speed adaptive single-phase reclosing. IEEE Transactions on Power Delivery, 28, 499-506.

12. Fitton, D. S., Dunn, R. W., Aggarwal, R. K., Johns, A. T., \& Bennett, A. (1996). Design and implementation of an adapative single pole autoreclosure technique for transmission lines using artificial neural networks. IEEE Transactions on Power Delivery, 11,748-756.

13. Elkalashy, N. I., Darwish, H. A., Taalab, A. M. I., \& Izzularab, M. A. (2007). An adaptive single pole autoreclosure based on zero sequence power. Electric Power Systems Research, 77, 438-446.

14. Khorashadi-Zadeh, H., \& Li, Z. (2011). Design of a novel phasor measurement unit-based transmission line auto reclosing scheme. IET Generation, Transmission \& Distribution, 5, 806.

15. Zahlay, F. D., \& Rama Rao, K. S. (2012). Neuro-prony and Taguchi's methodology-based adaptive autoreclosure scheme for electric transmission systems. IEEE Transactions on Power Delivery, 27, 575-582.

16. Radojevic, Z. M., \& Shin, J. R. (2007). New digital algorithm for adaptive reclosing based on the calculation of the faulted phase voltage total harmonic distortion factor. IEEE Transactions on Power Delivery, 22, 37-41.

17. Jamali, S., \& Parham a. (2010). New approach to adaptive single pole autoreclosing of power transmission lines. IET Generation, Transmission \& Distribution, 4, 115.

18. Ahn, S.-P., Kim, C.-H., Aggarwal, R. K., \& Johns, A. T. (2001). An alternative approach to adaptive single pole auto-reclosing in high voltage transmission systems based on variable dead time control. IEEE Transactions on Power Delivery, 16, 676-686.

19. Khodadadi, M., Noori, M. R., \& Shahrtash, S. M. (2013). A noncommunication adaptive single-pole autoreclosure scheme based on the acusum algorithm. IEEE Transactions on Power Delivery, 28, 2526-2533.

20. Keyvani, B., Karbalaye Zadeh, M., \& Lesani, H. (2014). Stability enhancement of multi-machine systems using adaptive reclosing of transmission lines. International Journal of Electrical Power \& Energy Systems, 62, 391-397.

21. Dudurych, I. M., Gallagher, T. J., \& Rosolowski, E. (2004). Arc effect on singlephase reclosing time of a UHV power transmission line. IEEE Transactions on Power Delivery, 19, 854-860.

22. Zengping, W. Z. W., Haofang, L. H. L., Yan, X. Y. X., Jing, M. J. M., \& Junling, L. J. L. (2006). Prediction method for preventing reclosing on permanent fault of shunt compensated EHV/UHV transmission lines. In 2006 IEEE Power Eng Soc Gen Meet (pp. 1-6).

23. Aggarwal, R. K., Song, Y. H., \& Johns, A. T. (1993). Adaptive single-pole autoreclosure scheme based on defining and identifying fault induced voltage waveform patterns. In Proceedings. joint international power conference Athens Power Tech (pp. 411-416). Athens: IEEE.

24. Upadhyay, P., Heistrene, L., \& Chandrasekaran, S. (2016). Design and implementation of adaptive autoreclosure for EHV transmission line. In International conference on microelectronics, computing and communication, MicroCom 2016.

25. Karacasu, O., \& Hakan Hocaoglu, M. (2011). An Adaline based arcing fault detection algorithm for single-pole autoreclosers. Electric Power Systems Research, 81, 367-376.

26. Dash, P. K. (1996). An adaptive linear combiner for on-line tracking of power system harmonics. IEEE Transactions on Power Systems, 11, 1730-1735.

27. Abdel-Galil, T. K., El-Saadany, E. F., \& Salama, M. M. A. (2003). Power quality event detection using Adaline. Electric Power Systems Research, 64, 137-144.

28. Ai, Q., Zhou, Y., \& Xu, W. (2007). Adaline and its application in power quality disturbances detection and frequency tracking. Electric Power Systems Research, 77, 462-469.

29. Marei, M. I., El-Saadany, E. F., \& Salama, M. M. A. (2004). Envelope tracking techniques for flicker mitigation and voltage regulation. IEEE Transactions on Power Delivery, 19, 1854-1861.

30. Min, L. C., \& Qing, L. (1997). An enhanced adaptive neural network contro scheme for power systems. IEEE Transactions on Energy Conversion, 12, 166-174. 
31. Terzija, V. V., \& Koglin, H. J. (2004). On the modeling of long arc in still air and arc resistance calculation. IEEE Transactions on Power Delivery, 19, 1012-1017.

32. Djurić, M. B., \& Terzija, V. V. (1995). A new approach to the arcing faults detection for fast autoreclosure in transmission systems. IEEE Transactions on Power Delivery, 10, 1793-1798.

33. Shao, W., Liu, Y., Wei, J. H., \& Li, Y. (2011). New algorithm for adaptive singlephase reclsoure on EHV transmission lines. In Asia-Pacific power and energy engineering conference, APPEEC.

34. Lin, D., Wang, H., Lin, D., \& He, B. (2015). An adaptive reclosure scheme for parallel transmission lines with shunt reactors. IEEE Transactions on Power Delivery, 30, 2581-2589.

35. Zhu, J., \& Zhou, N. (2015). Analysis of the fault type for adaptive singlephase autoreclosure. In 2015 IEEE power \& energy society general meeting. IEEE, Denver, CO, USA, pp. 1-5.

36. Moravej, Z., Pazoki, M., \& Khederzadeh, M. (2017). New smart fault locator in compensated line with UPFC. International Journal of Electrical Power \& Energy Systems, 92, 125-135.

37. Moravej, Z., Pazoki, M., \& Khederzadeh, M. (2015). New pattern-recognition method for fault analysis in transmission line with UPFC. IEEE Transactions on Power Delivery, 30:1231-1242

38. Jamali, S., \& Ghaffarzadeh, N. (2010). A wavelet packet based method for adaptive single-pole auto-reclosing. Journal of Zhejiang University SCIENCE C, 11, 1016-1024.

39. Li, B., Li, Y. L., Sheng, K., \& Zeng, Z. A. (2004). The study on single-pole adaptive reclosure of EHV transmission lines with the shunt reactor. In CSEE (pp. 52-56).

40. Khorashadi-Zadeh, H., \& Li, Z. (2007). Transmission line single phase auto re-closing scheme based on wavelet transform and adaptive fuzzy neuro inference system. In 2007 39th north American power symposium, NAPS (pp. 43-48)

41. El Shatshat, R., Salama, M. M. A., \& Kazerani, M. (2004). Artificial intelligent controller for current source converter-based modular active power filters. IEEE Transactions on Power Delivery, 19, 1314-1320.

42. Marei, M. I., El-Saadany, E. F., \& Salama, M. M. A. (2004). A processing unit for symmetrical components and harmonics estimation based on a new adaptive linear combiner structure. IEEE Transactions on Power Delivery, 19, 1245-1252.

43. Goli, R. K., Gafoor Shaik, A., \& Tulasi Ram, S. S. (2015). A transient current based double line transmission system protection using fuzzy-wavelet approach in the presence of UPFC. International Journal of Electrical Power \& Energy Systems, 70, 91-98.

44. Dehghani, M., Khooban, M. H., \& Niknam, T. (2016). Fast fault detection and classification based on a combination of wavelet singular entropy theory and fuzzy logic in distribution lines in the presence of distributed generations. International Journal of Electrical Power \& Energy Systems, 78, 455-462.

45. Livani, H., \& Evrenosoglu, C. Y. (2014). A machine learning and waveletbased fault location method for hybrid transmission lines. IEEE Transactions on Smart Grid, 5, 51-59.

46. Ngaopitakkul, A., \& Bunjongjit, S. (2013). An application of a discrete wavelet transform and a back-propagation neural network algorithm for fault diagnosis on single-circuit transmission line. International Journal of Systems Science, 44, 1745-1761.

47. Roy, N., \& Bhattacharya, K. (2015). Detection, classification, and estimation of fault location on an overhead transmission line using s-transform and neural network. Electric Power Components and Systems, 43, 461-472.

48. Yaozhong, G., Fonghai, S., \& Yuan, X. (1989). Prediction methods for preventing from single-phase reclosing on permanent fault. IEEE Transactions on Power Delivery, 4, 114-121.

49. Horowitz, S., \& Phadke, A. (1995). Power system relaying (2nd ed.). New York: Research Studies/Wiley.

50. Phadke, A. G. (1993). Synchronized phasor measurements in power systems. IEEE Computer Applications in Power, 6, 10-15.

51. Gajare, S., \& Pradhan, A. K. (2017). Synchrophasor-based intelligent autoreclosing scheme for series compensated transmission lines. IEEE Transactions on Power Delivery, 32, 2255-2262.

52. Zadeh, M. R. D., Voloh, I., Kanabar, M., \& Xue, Y. (2012). An adaptive HV transmission lines reclosing based on voltage pattern in the complex plane. In 2012 65th annual conference for protective relay engineers (pp. 85-95).
53. Kawady, T. A., Elkalashy, N. I., Ibrahim, A. E., \& Taalab, A. M. I. (2014). Arcing fault identification using combined Gabor transform-neural network for transmission lines. International Journal of Electrical Power \& Energy Systems, 61, 248-258.

54. Radojevic, Z., Terzija, V., Preston, G., Padmanabhan, S., \& Novosel, D. (2013). Smart overhead lines autoreclosure algorithm based on detailed fault analysis. IEEE Transactions on Smart Grid, 4, 1829-1838.

55. Burnett, R. O., Butts, M. M., \& Sterlina, P. S. (1994). Power system applications for phasor measurement units. IEEE Computer Applications in Power, 7, 8-13.

56. Price, E. (2006). Practical considerations for implementing wide area monitoring, protection and control. In 59th Annu Conf Prot Relay Eng 2006 (pp. 36-47)

57. Khorashadi Zadeh, H., \& Li, Z. (2011). Phasor measurement unit based transmission line protection scheme design. Electric Power Systems Research, 81, 421-429.

58. Radojević, Z., \& Terzija, V. (2007). Effective two-terminal numerical algorithm for overhead lines protection. Electrical Engineering, 89, 425-432.

59. Jannati, M., Vahidi, B., Hosseinian, S. H., \& Ahadi, S. M. (2011). A novel approach to adaptive single phase auto-reclosing scheme for EHV transmission lines. International Journal of Electrical Power \& Energy Systems, 33, 639-646.

60. Bhalja, B., \& Maheshwari, R. P. (2007). An adaptive distance relaying scheme using radial basis function neural network. Electric Power Components and Systems, 35, 245-259.

61. Liu, Z., Han, Z., Zhang, Y., \& Zhang, Q. (2014). Multiwavelet packet entropy and its application in transmission line fault recognition and classification. IEEE Transactions on Neural Networks and Learning Systems, 25, 2043-2052.

62. Jamali, S., \& Ghaderi Baayeh, A. (2017). Detection of secondary arc extinction for adaptive single phase auto-reclosing based on local voltage behaviour. IET Generation, Transmission \& Distribution, 11, 952-958.

63. Dias, O., \& Tavares, M. C. (2017). Comparison between traditional singlephase auto reclosing and adaptive technique based on harmonic content measurement. IET Generation, Transmission \& Distribution, 11, 905-914.

64. Nikoofekr, I., \& Sadeh, J. (2018). Nature of fault determination on transmission lines for single phase autoreclosing applications. IET Generation, Transmission \& Distribution, 12.

65. Jalilzadeh Hamidi, R., \& Livani, H. (2018). Adaptive single-phase autoreclosing method using power line carrier signals. International Journal of Electrical Power \& Energy Systems, 96, 64-73.

66. Luo, X., Huang, C., \& Jiang, Y. (2016). Improved digital algorithm for adaptive reclosing for transmission lines with shunt reactors. IET Generation, Transmission \& Distribution, 10, 2066-2070.

\section{Submit your manuscript to a SpringerOpen ${ }^{\circ}$ journal and benefit from:}

- Convenient online submission

- Rigorous peer review

- Open access: articles freely available online

- High visibility within the field

- Retaining the copyright to your article

Submit your next manuscript at $>$ springeropen.com 